\title{
Article
}

\section{Typology Selection of Retaining Walls Based on Multicriteria Decision-Making Methods}

\author{
Belén Muñoz-Medina ${ }^{1, * \mathbb{D}}$, Javier Ordóñez ${ }^{2}$, Manuel G. Romana ${ }^{1}$ and Antonio Lara-Galera ${ }^{1}$ \\ 1 School of Civil Engineering, Universidad Politécnica de Madrid, 28040 Madrid, Spain; \\ manuel.romana@upm.es (M.G.R.); antoniolorenzo.lara@upm.es (A.L.-G.) \\ 2 School of Civil Engineering, University of Granada, 18071 Granada, Spain; javiord@ugr.es \\ * Correspondence: mariabelen.munoz@upm.es; Tel.: +34-91-0674146
}

Citation: Muñoz-Medina, B.;

Ordóñez, J.; Romana, M.G.;

Lara-Galera, A. Typology Selection of Retaining Walls Based on

Multicriteria Decision-Making

Methods. Appl. Sci. 2021, 11, 1457.

https://doi.org/10.3390/app11041457

Academic Editors: Asterios Bakolas and Bożena Hoła

Received: 16 December 2020

Accepted: 2 February 2021

Published: 5 February 2021

Publisher's Note: MDPI stays neutral with regard to jurisdictional claims in published maps and institutional affiliations.

Copyright: (c) 2021 by the authors. Licensee MDPI, Basel, Switzerland. This article is an open access article distributed under the terms and conditions of the Creative Commons Attribution (CC BY) license (https:// creativecommons.org/licenses/by/ $4.0 /)$

\begin{abstract}
In civil engineering and construction, in the selection of the most adequate and sustainable alternative, all of the alternatives and selection criteria, such as the requirements of the construction process (which are often overlooked) and the preferences of designers, clients, or contractors, are not always taken into account. The purpose of this article is to suggest a methodology that may allow studying all of the possible alternatives to find the most ideal solution among all of the existing possibilities for the selection of retaining walls to be built in infrastructures in different environments. For this purpose, all typologies of retaining walls and selection criteria (external requirements, construction requirements, characteristics of the natural land and economic criteria) are first identified. Subsequently, a simple methodological method is proposed, allowing the relative importance of each criterion to be established and allowing us to select the most suitable solution for each situation by successively applying different multicriteria decision-making methods. Finally, the methodology developed is applied to two projects in different locations with different constraints. The results obtained provide a set of compromise solutions that remain as best-rank alternatives when the weights of the criteria change. Therefore, the methodology developed can be applied to the selection of typologies of other structures in future projects.
\end{abstract}

Keywords: multicriteria decision-making; retaining wall; selection criteria; construction requirements; AHP method; VIKOR method; TOPSIS method

\section{Introduction}

A retaining wall could be defined as any uninterrupted structure that, whether in a passive or in an active way, produces a stabilizing effect over a mass of land [1]. The earth retaining walls are those structures that retain a piece of land with a steeper angle than the angle of friction of the land [2]. There are different classifications of retaining walls according to different criteria: load support mechanism (externally or internally stabilized walls), construction concept (fill or cut), system rigidity (rigid or flexible), and service life (permanent or temporary) [3]. Thus, several different types of retaining walls exist with different performance characteristics as well as constructability characteristics, as well as different uses [2]. Retaining walls are expensive structures that are designed and constructed to support cut and fill slopes where space is not available for construction of flatter, more stable slopes [3]; therefore, the cost of construction, the environment and the space available will be criteria to take into account in its design and construction. Selecting a type of retaining wall is a complex process, considering the various geotechnical and non-geotechnical factors involved [4]. Moreover, during the selection process, it is necessary to consider all the criteria during the whole life cycle [5].

In decision-making, it is necessary to consider all the alternatives and criteria involved in the decision process [6]. In civil engineering and construction, the choice of the most adequate and sustainable alternative is not always made by studying all of the possible typologies nor the life cycle of the infrastructure: design, construction, maintenance, and 
dismantlement. Therefore, it is necessary to identify all the typologies, their characteristics, and the selection criteria without forgetting the requirements of the construction process. The methodology to be developed must establish a systematic process in the decisionmaking process. Finally, the solutions obtained must remain unchanged in the face of changes in the decision-maker's preferences or variation in the weight of criteria, i.e., provide strong solutions.

Multicriteria decision-making methods have become a tool to solve engineering problems because they allow complex problems to be modeled. These methods can be used to select the best alternatives when there are several conflicting criteria in a context of uncertainty [7]. In this paper, a methodology is developed for the selection of typology of retaining walls according to different criteria. In the developed methodology, the first step is taken has been to identify all of the different types of retaining walls and selection criteria (external requirements, construction requirements, characteristics of the natural land, and economic criteria) that may determine whether a solution is the best option or not, and to which extent. Subsequently, the most suitable solution is determined by successively applying different multicriteria decision-making methods.

\section{Literature Review}

\subsection{Retaining Walls}

Retaining walls are constructed to sustain the lateral pressure of the earth behind them. They are structures used to contain soil or other loose materials when their natural steeps are undesirable, in the case when building linear infrastructures such as railways or roads [5]. Retaining walls are often an overlooked critical asset of infrastructures because they are constantly around us. Each year, globally, millions of square meters of retaining walls are constructed for private and public projects. Retaining walls save space, reduce impacts, and allow owners to get the most out of a given property or right-of-way. Thus, retaining walls are an important part of development projects today [8].

There are many kinds of retaining walls, with different forms and structural characteristics according to the dimensions and location [9]. Over the last three to four decades, due to the development of materials and enhancement in technical understanding of geotechnical engineering, different types of soil retention systems have evolved [10]. There are several classifications of types of earth retaining structures.

In general terms, these structures may be classified into two groups, externally stabilizes walls and internally stabilized walls. The examples of first category are gravity walls, reinforced concrete cantilever and reinforced concrete counterfort walls. These walls are essentially characterized by the concept that the lateral earth pressures due to self-weight of the retained fill and accompanied surcharge loads are carried by the structural wall [10]. The construction sequence of these walls involves the casting of base and stem followed by backfilling with specified material. This requires a considerable amount of time as concrete has to be adequately cured and sufficient time spacing has to be allowed for concrete of previous lift to gain strength before the next lift is cast [10]. The internally stabilized walls include metal strip walls, geotextile reinforced walls and anchored earth walls. These walls comprise of horizontally laid reinforcements which carry most or all of the lateral earth pressure via soil-reinforcement interaction or via passive resistance from the anchor block [10]. This reduces the volume of concrete and steel reinforcement in the wall significantly, thus its construction is relatively fast speed. Retaining walls with relief shelves can be considered as a special type of retaining wall [11].

Another classification establishes three different groups: gravity walls, embedded walls and hybrid walls [2].

- Gravity walls: The purpose of a gravity wall is to avoid sliding and overturns throughout its own weight and by the friction of its base with the land. They are generally built over flat land before being refilled behind the wall. Given their characteristics, they are generally used in high lands, as per example, for retaining embankments in roads and railways. They can also be used in order to support excavations, which are 
under the natural level of the land. For these situations, the excavation is made in open air and the refilling is done behind the wall. These walls require an additional excavation and refill, as well as the occupation of the land during construction. One of the basic characteristics of the gravity walls is that the drainage is done through drain tubes located behind the wall with the purpose of reducing the water pressure.

- Embedded walls: An embedded wall is the one which base penetrates in the land to achieve side support of the passive resistance of the land on the lower front part of the wall. This resistance can be used as a sole resistance to provide stability to the wall or it can also be used with moorings, supports or other support sources of side support to increase the stability. In this case, they are considered anchored walls or underpinned walls. Unlike with gravity walls, building embedded walls requires specialized equipment and in-situ operations. These walls need to be built before starting the excavation. It is preferred to use embedded walls rather than gravity walls, when:

- It is necessary to make deep excavations.

- It is not possible to temporarily occupy adjoining lands in order to make temporary excavations in open air.

- There are buildings or structures close to the excavation that need to be supported or protected.

- If there is a high phreatic level and it needs an excessive pumping in order to eliminate the water for making a temporary excavation in open air.

- Hybrid walls: These are the ones that combine different aspects of both gravity walls and built-in walls or slurry walls for retaining the land. An example of a hybrid wall would be a concrete wall built forming an $\mathrm{L}$ or $\mathrm{T}$, with pile foundations.

A subclassification of these types of retaining walls is included in Table 1.

Table 1. Types of retaining walls. Source: the authors' own research.

\begin{tabular}{|c|c|c|}
\hline Type of Retaining Wall & Sub-Type of Retaining Wall & Main Characteristics \\
\hline Gravity wall & Mass concrete wall & It uses its own weight for stabilizing, it does not use any traction \\
\hline Gravity wall & Reinforced concrete wall & $\begin{array}{l}\text { They can be constructed in an L or T shape with a stabilizing } \\
\text { platform, with buttresses, made in situ or prefabricated }\end{array}$ \\
\hline Gravity wall & Ashlar factory walls & $\begin{array}{c}\text { They are stone walls, ashlar masonry, placed one together with } \\
\text { another }\end{array}$ \\
\hline Gravity wall & Masonry walls & Walls formed by coined rough stones \\
\hline Gravity wall & Riprap walls & $\begin{array}{l}\text { Walls formed by irregular stone blocks, which are generally } \\
\text { obtained from a quarry, with different shapes and rough surfaces. }\end{array}$ \\
\hline Gravity wall & Crib walls & $\begin{array}{l}\text { Walls comprise a grillage of header and stretcher units placed on } \\
\text { firm foundations, usually of mass or reinforced concrete }\end{array}$ \\
\hline Gravity wall & Gabion walls & $\begin{array}{l}\text { Walls formed by superimposed boxes of prismatic form of wired } \\
\text { (galvanized) reinforcing mesh refilled with small rocks. }\end{array}$ \\
\hline Gravity wall & Green walls & $\begin{array}{l}\text { Solid masses of earth reinforced with geotextiles. They do not } \\
\text { generally need any foundation. Complete landscape integration. }\end{array}$ \\
\hline Gravity wall & Garden walls & $\begin{array}{l}\text { Walls formed by a grid of concrete elements placed over a } \\
\text { concrete base }\end{array}$ \\
\hline Gravity wall & Wooden garden walls & $\begin{array}{c}\text { Walls formed by wooden pieces put in place and which interior is } \\
\text { refilled with earth }\end{array}$ \\
\hline Gravity wall & Prefabricated concrete walls & $\begin{array}{l}\text { Walls with the form of an } \mathrm{L} \text {. The panel and footing have been } \\
\text { conjointly prefabricated forming a sole element. They have a } 4 \\
\text { meters height limit. Transport limitations }\end{array}$ \\
\hline Gravity wall & $\begin{array}{c}\text { Concrete prefabricated blocks } \\
\text { walls }\end{array}$ & $\begin{array}{l}\text { Green: Formed by prefabricated empty pieces to be filled with } \\
\text { sand Blocks of solid mass, which have been fit together. There is a } \\
\text { great typology of blocks }\end{array}$ \\
\hline Gravity wall & Slat walls & $\begin{array}{l}\text { Formed by prefabricated transversal plates, placed between } \\
\text { vertical buttresses. They usually have a vegetal cover. }\end{array}$ \\
\hline
\end{tabular}


Table 1. Cont.

\begin{tabular}{|c|c|c|}
\hline Type of Retaining Wall & Sub-Type of Retaining Wall & Main Characteristics \\
\hline Gravity wall & Reinforced soil & $\begin{array}{l}\text { It is a special gravity wall. The gravity structure is provided by } \\
\text { reinforcing the ground itself rather than providing a separate } \\
\text { structure }\end{array}$ \\
\hline Embedded wall & Traditional embedded walls & $\begin{array}{l}\text { Wall penetrates the ground at its base to gain lateral support from } \\
\text { the passive resistance of the ground in front of the lower part of } \\
\text { the wall. This resistance may be or act in conjunction with } \\
\text { anchorages, props or other sources of lateral support for stability }\end{array}$ \\
\hline Embedded wall & Sheet pile walls & $\begin{array}{l}\text { Walls are constructed by driving, vibrating or pressing steel } \\
\text { sheets into the ground without any material being removed }\end{array}$ \\
\hline Embedded wall & $\begin{array}{l}\text { Contiguous o secant bored } \\
\text { pile walls }\end{array}$ & $\begin{array}{l}\text { Pile wall consists of bored cast-in-place piles installed along the } \\
\text { line of the wall }\end{array}$ \\
\hline Embedded wall & Diaphragm walls & $\begin{array}{l}\text { Diaphragm walls are interlocking reinforced-concrete panels. The } \\
\text { panels are formed by excavation under fluid to support the } \\
\text { surrounding ground and lowering a prefabricated reinforce-ment } \\
\text { cage into the trench excavation }\end{array}$ \\
\hline
\end{tabular}

\subsection{Multicriteria Decision-Making}

V. Neumann-Morgenstern (1943) works represent the starting point of the scientific treatment of the individual decision-making process problems [12]. The decision-making process can be done by applying different methods and tools, as well as using different objectives [13]. The use of multicriteria decision-making (MCDM) methods constitutes an efficient tool for reducing subjectivity and systematizing the decision-making process [14]. They can be used in different stages of the process, either to decide on the importance of the criteria for each alternative, to select the most suitable alternative or to establish a ranking of alternatives. Thus, MCDM methods can be used to select the best alternatives when there are several conflicting criteria in a context of uncertainty [7]. MCDM methods have had a fast-growing in many disciplines [15].

In a decision-making problem there are always several elements: Decision criteria $C$ $=\left\{C_{1}, C_{2}, \ldots C_{n}\right\}$, conditions which allow us to differentiate alternatives and to establish the preferences of the decision-maker; Weight or measurements of the importance of the criteria for the decision-maker, being each criteria vector associated to a weight vector $[w]=\left(w_{1}, \ldots w_{\mathrm{n}}\right)$. Weights can be established by direct allocation methods or by other methods as Simos method [16], Delphi method [17] or by paired comparisons, analytic hierarchy process (AHP) [18] among others. Alternatives, different solutions to be adopted in a decision-making problem, which are assigned as, $A s=\left\{A_{1}, A_{2}, \ldots A_{m}\right\}(I=1,2, \ldots m)$ are the possible alternatives. And last, the assessment or decision matrix, by which, for all of the criteria taken into account and for each alternative of the choice ensemble, the decision-maker is able to give a numeric or symbolic $a_{i j}$ value that expresses an assessment or opinion of the alternative $\mathrm{A}_{i}$ regarding criteria $C_{j}$ [19].

The MCDM methods can be classified into different groups according to similar characteristics [13]. These groups are: (1) Scoring methods, their basis consists of assessing the alternatives using basic arithmetical operations, including the simple additive weighting (SAW) and the complex proportional assessment (COPRAS) methods obtain the sum of the weighted normalized values of all the criteria [20]; (2) distance-based methods, the basic principle of them is obtaining the distance among each alternative and a specific point (a hypothetical best alternative), including technique for order preference by similarity to an ideal solution (TOPSIS) and the viekriterijumsko kompromisno rangiranje (VIKOR) methods [21-23]. This group also includes others based on Euclidean distance measurement $[24,25]$. (3) Pairwise comparison methods are widely used for their ease of calculation when selecting different alternatives in case there are quantitative and qualitative criteria. They allow evaluating the different alternatives according to qualitative criteria when comparing them in pairs and they are sometimes used to weigh the selection criteria as it 
is the case in this paper. The best-known method of this group is the Analytic Hierarchy Process (AHP) method [18]. Other methods in this group are Analytic Network Process (ANP) $[26,27]$ and Measuring Attractiveness by a Categorical Based Evaluation Technique (MACBETH) [28,29] methods. (4) Outranking methods, this term includes all those MCDM methods that revolve around the theoretical concept of relationships of achievement, proposed by a group of French researchers in the mid-1960s. The first representative of the methods of overcoming was the ELimination Et Choix Traduisant la REalité (ELECTRE) method [30,31]. Another widely used method included in the outranking methods is the Preference Ranking Organization METHod for Enrichment Evaluations (PROMETHEE) method, was introduced by Brans and Vincke (1985) and Brans et al. Since then, numerous applications with a special interest in location problems have appeared: hydropower plants, commercial facilities in a competitive environment, waste disposal sites, financial evaluation, etc. [32].

There already are some precedent uses of MCDM methods in order to choose the type of retaining wall, such as the case of the Transportation Department of South Carolina in USA [3]. In this case, the determination of the most acceptable type is made based on the Important Selection Factor, ISF, rating and the weighted rating each of the above selection factors is given for each retaining wall type. Where the ISF ratio varies between 1: least important factor and 3: most important factor, that is to say, it is a qualitative evaluation. Likewise, for the selection of the most suitable construction solution of retaining walls on construction lands, other precedent selection uses have been included in the bibliography although not studied in this review-, such as decision trees using logistic regression analysis, for the selection of walls [4]. In this paper, also all decision criteria are identified including construction requirements or requirements of the construction process.

\section{Methodology}

Description of the problem:

- Question to be answered; which is the most suitable retaining wall to be chosen for certain infrastructures?

- We have different alternatives for the resolution $\left(\mathrm{A}_{j}\right)$, which are the different typologies of retaining wall constructions.

- The solution is conditioned by a series of criteria, project and construction requirements $\left(C_{i}\right)$, although not all criteria have the same importance regarding the decision. Therefore, they must be analyzed for each case depending on weights $\left(w_{i}\right)$.

- If we were to represent the problem based on a matrix, we would obtain a matrix by which $a_{j i}$ would be the obtained assessments for each alternative $\left(\mathrm{A}_{j}\right)$, depending on the criteria $\left(C_{i}\right)$.

Once the problem has been defined, Figure 1 includes an outline of the steps in the decision process [33]. This process is followed by the methodology developed and described in this section.

\subsection{Selection Criteria}

To make correct use of the MCDM method, apart from identifying all the alternatives (in this case the types of retaining walls), it is required to identify all characteristics and requirements of the project and the construction process that may influence the selection of the most suitable typology. The project and construction requirements can be divided into five main groups: external requirements, requirements of the construction process, characteristics of the natural land, environmental and economic criteria. These criteria have been listed in Table 2. Some criteria are quite easy to incorporate, analyze and assess, such as the cost criteria, or the performance, which have quantitative assessments, but others, such as the culture (based on the frequency with which certain types of retaining walls are chosen in certain geographical areas), or the influence of the drainage, is not as easy and clear to analyze or assess. 


\begin{tabular}{|c|}
\hline -Definition of the problem \\
\hline $\begin{array}{l}\text {-Establishing objectives: general declarations of intentions and desirable values. } \\
\text { For example: lowest cost and best landscape integration }\end{array}$ \\
\hline -Identifying alternatives \\
\hline -Definition of criteria \\
\hline -Selection or design of a multicriteria decision making method \\
\hline $\begin{array}{l}\text { - Evaluation of the alternatives for each criteria, consideration of criterion and } \\
\text { prioritization of alternatives }\end{array}$ \\
\hline -Validation of the solution \\
\hline
\end{tabular}

Figure 1. Steps or stages of the decision-making process.

Table 2. Selection criteria. Source: the authors' own research.

\begin{tabular}{|c|c|c|c|}
\hline Group & Criteria & Type of Criterion & Relevance \\
\hline External requirements & Retaining wall dimensions & Quantitative & High \\
\hline External requirements & Space available & Quantitative & High \\
\hline External requirements & Traffic restrictions & Qualitative & Medium \\
\hline External requirements & Influence on public services & Qualitative & High \\
\hline External requirements & Space available in the base of the wall & Quantitative & Medium \\
\hline External requirements & Permissible settlement & Quantitative & High \\
\hline External requirements & On-site overloading & Quantitative & High \\
\hline External requirements & Seismicity & Quantitative & High \\
\hline External requirements & Permeability & Quantitative & Medium \\
\hline External requirements & Aesthetic appearance & Qualitative & Low \\
\hline External requirements & Technical culture and customs & Qualitative & Medium \\
\hline Environmental & Noise and vibration during construction & Quantitative & Medium \\
\hline Environmental & Construction and demolition residues & Quantitative & High \\
\hline Environmental & Landscape integration & Qualitative & High \\
\hline Environmental & $\begin{array}{c}\text { Energy use and greenhouse gas emissions (life } \\
\text { cycle) }\end{array}$ & Quantitative & High \\
\hline Construction requirements & Construction performance & Quantitative & High \\
\hline Construction requirements & $\begin{array}{c}\text { Elements inside the ground: round stones, gravel, } \\
\text { debris }\end{array}$ & Qualitative & Low \\
\hline Construction requirements & Surface disturbances & Qualitative & Low \\
\hline Construction requirements & Machinery and specialized equipment & Qualitative & High \\
\hline Construction requirements & Spaces for material storage & Quantitative & Medium \\
\hline Construction requirements & Material availability & Quantitative & Medium \\
\hline Characteristics of the soil natural & Density of the retained material & Quantitative & Medium \\
\hline Characteristics of the soil natural & Interstitial water pressure & Quantitative & Medium \\
\hline Characteristics of the soil natural & Soil resistance (internal angle of friction) & Quantitative & High \\
\hline Economic criteria & Construction cost & Quantitative & High \\
\hline Economic criteria & Preservation and maintenance necessities & Quantitative/Qualitative & High \\
\hline
\end{tabular}

\subsection{MCDM Methods}

A methodology for resolving the problem has been set out, combining two multiplecriteria decision-making methods, the analytic hierarchy process (AHP) and the VIKOR methods. The obtained selection will be compared with the one resulting when applying the TOPSIS method in substitution of the VIKOR method. Both methods are focused on trying to find the solution that is closest to the optimal solution but with a different process of evaluation [21]. 
By the analytic hierarchy process (AHP), the weight eigenvector is calculated for the criteria that determine which is the most ideal solution, by making a paired comparison of them for each project [34]. It must be taken into account that the weight eigenvector is not the same for each project, since certain criteria may have bigger importance in comparison to the others, depending on the characteristics of the project. We must remember that AHP measures the global inconsistency of the views by the consistency ratio (CR), calculated by dividing the consistency index $(\mathrm{CI})$ and the random index (RI), and it should be of less than $10 \%$. The consistency index measures the consistency of the comparison matrix [18].

$$
C I=\frac{\lambda_{\max }-n}{n-1}
$$

where $\lambda_{\max }$ is the biggest value of the transposed matrix of the paired comparison matrix, and $\mathrm{n}$ is the matrix range. The RI is an index which measures the consistency of a random matrix $[18,35]$. On the other hand, through paired comparisons we can establish the "behavior" of each alternative for each of the qualitative criteria that are part of the makingdecision processes, to obtain a quantitative assessment for qualitative criteria.

Later, the VIKOR method will be applied for selecting the most suitable typology, based on a classification list of alternatives that shall provide us with one or more compromise solutions. "Viekriterijumsko kompromisno rangiranje" (VIKOR) is a Serbian term meaning multicriteria optimization and compromise solution [23]. It was developed to solve a decision problem with a limited number of alternatives (possible solutions) with conflicting criteria and with different units of measurement [22]. Therefore, the VIKOR method is suitable for solving decision-making problems with conflicted and noncommensurable criteria (which means, with different units) or when there are quantitative and qualitative criteria. The VIKOR method has been applied on many occasions for selection of alternatives in infrastructures, as reflected in the literature [36-40]. For normalization, converting the criteria into dimensional variables, a linear function is used in the VIKOR method that does not depend on a function of value of criteria as in the case of TOPSIS method [21]. The compromise solution shall be the one closest to the optimal solution [22]. To obtain a compromise solution (or solutions), we shall follow the next steps:

1. "Best" and "worst" value of each alternative is calculated for each criterion, as follows:

$$
\begin{gathered}
f_{i}^{*}=\max _{i} f_{j i} ; \quad f_{i}^{-}=\min _{i} f_{j i} ; \text { If criterion i represents a benefit } . \\
f_{i}^{*}=\min _{i} f_{j i} ; f_{i}^{-}=\max _{i} f_{j i} \text { If criterion i represents a cost. }
\end{gathered}
$$

where $i$ is the number of criteria and $j$ is the number of alternatives, so $f_{j i}$ is an evaluation of the alternative $\mathrm{A}_{j}$ with respect to criterion $C_{i}$.

2. Values $S_{j}, R_{j}$, and $Q_{j}$ are calculated for each alternative as follows:

$$
\begin{gathered}
S_{j}=\sum_{i=1}^{n} w_{i}\left(f_{i}^{*}-f_{j i}\right) /\left(f_{i}^{*}-f_{i}^{-}\right) \\
R_{j}=\max _{i}\left|w_{i}\left(f_{i}^{*}-f_{j i}\right) /\left(f_{i}^{*}-f_{i}^{-}\right)\right|
\end{gathered}
$$

where $w_{i}$ is the weight of criterion $i$ relative to the rest, that is, it reflects the relative importance of each criterion. At this point, it is necessary to indicate that in the VIKOR method the normalized values are given by the expression: $\left(f_{i}^{*}-f_{j i}\right) /\left(f_{i}^{*}-\right.$ $f_{i}^{-}$). Thus, normalized values do not depend on the unity of the different criteria [21].

$$
Q_{j}=\vartheta\left[\left(S_{j}-S^{*}\right) /\left(S^{-}-S^{*}\right)\right]+(1-\vartheta)\left[\left(R_{j}-R^{*}\right) /\left(R^{-}-R^{*}\right)\right]
$$

where $S^{*}=\min _{j} S_{j}, S^{-}=\max _{j} S_{j}, R^{*}=\min _{j} R_{j}, R^{-}=\max _{j} R_{j}$, and $\vartheta$ represent weight of the strategy of "the majority of criteria" (or "the maximum group utility"). Consensus is for a value $\vartheta=0.5$ [21]. Other authors have demonstrated how difficult it is to 
achieve consensus in situations of uncertainty and with large amounts of information and possible alternatives [41].

3. Different alternatives are sorted according to values $S, R$ and $Q$ and the results are three ranking lists.

4. Best-ranked alternative $\mathrm{A}(1)$ is identified as a compromise solution, i.e., the alternative with the lowest value of $Q$. This is true, if the following two conditions are met:

Requirement 1: Acceptable advantage.

$Q(\mathrm{~A}(2))-Q(\mathrm{~A}(1)) \geq \mathrm{DQ}$, where besides $\mathrm{A}(2)$ is the second alternative according to the value classification of $Q$, and $\mathrm{DQ}=1 /(\mathrm{J}-1)$, where $\mathrm{J}$ represents the number of alternatives.

Requirement 2: Acceptable stability in the decision-making process.

Alternative $A(1)$ will also be the best ranked according to the list of values of $S$ and/or $R$. This alternative solution is stable within a decision-making process.

If one of the requirements is not met, the method offers a range of alternative solutions, which can consist of: Alternatives $\mathrm{A}(1)$ and $\mathrm{A}(2)$, if condition 2 is not met; Alternatives $\mathrm{A}(1), \mathrm{A}(2), \ldots \mathrm{A}(\mathrm{M})$, if condition 1 is not met; $\mathrm{A}(\mathrm{M})$ will be established taking into account the relation $Q(\mathrm{~A}(\mathrm{M}))-Q(\mathrm{~A}(1))<\mathrm{DQ}$. These alternatives are considered to be within the "closeness" [21,22].

The VIKOR method is an efficient tool to use as a multiple-criteria decision-making method when the decision-maker is not able to, or does not know how to, express their preferences at the beginning of the design process. The obtained compromise-solution may be approved by the decision-maker, given that it provides the biggest group usefulness to the majority, represented by the minimum $S$, and an individual minimum opposition represented by the minimum $R$ [22].

Later, the TOPSIS method shall be applied in order to compare the results obtained by both methods. In order to do this we start with the decision matrix and we calculate the positive optimal solution and the negative optimal solution, and we will obtain the best ranked solution, being the one that is closer to the positive optimal solution, and further from the negative optimal solution [42,43]. To carry out the simulation and application of the VIKOR and TOPSIS methods, an algorithm has been developed in the MATLAB ${ }^{\circledR}$ software to automate the calculations.

\section{Case Study}

The described methodology is applied to two projects with different context and purpose. Project 1: Mountain road in a nature park in the province of Madrid (Spain) and Project 2: New highway under construction in Andalusia (Spain).

Validity will be verified by the behavior in the solution to be adopted when there are variations in the weight of criteria, the changes in the compromise solution will be determined using the VIKOR method. And lastly, the results will be compared to the obtained results using the TOPSIS method.

A small set of criteria and typologies have been taken into account to show the methodology simply. As alternatives are considered, four typologies included in Table 2: a reinforced concrete wall built in situ, garden wall, green wall reinforced with geotextiles, and riprap wall. These typologies have been selected given that they represent a bigger variety of retaining walls. In the decision-making process, we choose as determining criteria the following: construction cost in $€ / \mathrm{m}$, construction performance, $\mathrm{m} /$ day, landscape integration, technical culture and customs (construction frequency), and lastly, preservation and maintenance necessities. In a manner similar to that of the selection of alternatives, these five criteria were chosen because they are the most common and determining in retaining walls. All retaining walls have an average height of four meters. To apply the decision-making methodology, the following hypotheses are needed:

- All the retaining walls have a stable structure (the assessed solutions are stable).

- Logistic determinants have not been considered such as material availability or available space for gatherings.

- The drainage system works correctly in all cases 
- Selection criteria are independent.

To evaluate the different alternatives concerning the selection criteria, firstly the cost and performance of construction has been determined based on the advice of suppliers, Spanish Ministry of Development [1,44], as well as the advice of designers and contractors who were consulted for this purpose. Next, for the quantitative evaluation of the different alternatives for the qualitative criteria: technical culture and customs and preservation and maintenance necessities, paired comparisons according to the Saaty scale of the AHP method [18,35] are used to determine such a quantitative assessment. In this way, the quantitative assessment of each alternative for each qualitative criterion varies between 0 and 1 , with 0 being the lowest value and 1 the highest value for each criterion. The results obtained for each alternative respect to each selection criterion have been included in Table 3. If these results are analyzed, it can be seen that, for example, the alternative of reinforced concrete retaining wall is the one which obtains the lowest valuation concerning the criterion of landscape integration, is the one that is built most frequently and, on the contrary, is the alternative which requires the least conservation and maintenance actions throughout the life cycle.

Table 3. Data and values of alternative for each criterion. Source: the authors' own research.

\begin{tabular}{cccccc}
\hline Alternative & $\begin{array}{c}\text { Construction } \\
\text { Cost }(\boldsymbol{\epsilon} / \mathbf{m})\end{array}$ & $\begin{array}{c}\text { Construction } \\
\text { Performance (m/Day) }\end{array}$ & $\begin{array}{c}\text { Landscape } \\
\text { Integration }\end{array}$ & $\begin{array}{c}\text { Technical Culture } \\
\text { and Customs }\end{array}$ & $\begin{array}{c}\text { Preservation and } \\
\text { Maintenance } \\
\text { Neccesities }\end{array}$ \\
\hline $\begin{array}{c}\text { Reinforced concrete } \\
\text { retaining wall }\end{array}$ & 870 & 1.5 & 0.041 & 0.506 & 0.047 \\
Garden retaining wall & 640 & 2.48 & 0.099 & 0.257 & 0.316 \\
Green retaining wall & 430 & 2.75 & 0.608 & 0.065 & 0.564 \\
Riprap retaining wall & 608 & 2.8 & 0.251 & 0.172 & 0.073 \\
\hline
\end{tabular}

Once the assessment of the alternatives has been determined, the values $f_{i}{ }^{*}$ and $f_{i}{ }^{-}$, being the best and worst values of each criteria function, are calculated according to the VIKOR method. The results are included in Table 4.

Table 4. Values $f_{i}^{*}$ and $f_{i}{ }^{-}$, applicating step 1 of the viekriterijumsko kompromisno rangiranje (VIKOR) method Source: the authors' own research.

\begin{tabular}{cccccc}
\hline & $\begin{array}{c}\text { Construction Cost } \\
(\boldsymbol{\epsilon} / \mathbf{m}) \text { Minimum }\end{array}$ & $\begin{array}{c}\text { Construction } \\
\text { Performance }(\mathbf{m} / \text { day) } \\
\text { Maximum }\end{array}$ & $\begin{array}{c}\text { Landscape } \\
\text { Integration } \\
\text { Maximum }\end{array}$ & $\begin{array}{c}\text { Technical Culture } \\
\text { and Customs } \\
\text { Maximum }\end{array}$ & $\begin{array}{c}\text { Preservation and } \\
\text { Maintenance } \\
\text { Necessities Minimum }\end{array}$ \\
\hline$f_{i}{ }^{-}$ & 430 & 2.8 & 0.608 & 0.506 & 0.047 \\
$f_{i}{ }^{-}$ & 870 & 1.5 & 0.041 & 0.065 & 0.564 \\
\hline
\end{tabular}

It is important to highlight that the importance of each criterion depends on the location where the retaining wall is going to be constructed. Thus, for each project, and before using the VIKOR and TOPSIS methods, the weight vector is determined, by paired comparisons, and by applying the AHP. So, for project 1 , given the environmental factors, when using the AHP method for obtaining the weight vector by paired comparisons, the weight vector is obtained, $w=(0.03 ; 0.08 ; 0.54 ; 0.21 ; 0.13)$. It is important to remember that the consistency of the comparison matrix must be identified. After determining the consistency following equation (1), the consistency ratio $=0.094697$, which is under 0.1 , is obtained. Therefore, the assessments made can be considered as consistent.

Then, Equations (2)-(4) are applied to calculate the $S_{j}, R_{j}$ and $Q_{j}$ values. The alternatives classification list will be established according to the values of $S, R$ and $Q$, to establish the solution or the ensemble of compromise solutions. To carry out the simulation and application of the VIKOR and TOPSIS methods, an algorithm has been developed in the 
Matlab ${ }^{\circledR}$ software to automate the calculations. The results obtained by VIKOR method are shown in Table 5:

Table 5. Ranking of alternatives according to the VIKOR method. Project 1. Source: the authors' own research.

\begin{tabular}{cccc}
\hline Alternative & $\boldsymbol{Q}$ & $\boldsymbol{S}$ & $\boldsymbol{R}$ \\
\hline Green retaining wall & 0.000 & 0.346 & 0.210 \\
Riprap retaining wall & 0.437 & 0.521 & 0.341 \\
Garden retaining wall & 0.917 & 0.711 & 0.487 \\
Reinforced concrete retaining wall & 0.925 & 0.657 & 0.542 \\
\hline
\end{tabular}

Minimum value of $Q$ can be observed for the green wall alternative (see Table 5). Both requirements of the VIKOR method are met: requirement 1 , acceptable advantage, and requirement 2 , stability of the decision-making process. Therefore, there is a compromise solution for the decision-making problem described here, being the alternative of green wall reinforced with geotextile the one most suitable to the determining criteria.

To verify the validity of the method, the VIKOR method is applied for another case varying the importance of the different criteria but keeping the criterion of landscape integration as the most important, with the weight between 0.48 and 0.54 . Thus, it is confirmed as compromise solution the typology of the green wall, being the best-ranked option in the classification lists $Q, S$ and $R$, although within an ensemble of compromise solutions in which a riprap wall is also included as the second option. When using TOPSIS, the green retaining wall is confirmed as the best-ranked solution, obtaining the following classification: Green retaining wall, $R_{j}=0.9966$; Riprap retaining wall, $R_{j}=0.5955 ;$ Garden retaining wall, $R_{j}=0.5227$; Reinforced concrete retaining wall, $R_{j}=0.0034$.

For project 2, the process followed in the previous case must be repeated, calculating on first place the weight matrix for the selection criteria, by paired comparisons. The weight vector obtained is $w=(0.41 ; 0.03 ; 0.26 ; 0.11 ; 0.18)$. The consistency of the comparison matrix has been assessed, obtaining a Consistency Ratio of less than 0.1 , being able now to conclude that the assessments made are consistent. In the same way, we complete the decision-making process by calculating the values $S_{j}, R_{j}$ and $Q_{j}$ and establishing the classification lists of alternatives, Table 6.

Table 6. Ranking of alternatives according to the VIKOR method. Project 2. Source: the authors' own research.

\begin{tabular}{cccc}
\hline Alternative & $Q$ & $S$ & $R$ \\
\hline Green retaining wall & 0.034 & 0.294 & 0.182 \\
Riprap retaining wall & 0.158 & 0.424 & 0.166 \\
Garden retaining wall & 0.514 & 0.598 & 0.237 \\
Reinforced concrete retaining wall & 1.000 & 0.707 & 0.409 \\
\hline
\end{tabular}

As a result, a minimum of the $Q, S$ and $R$ values for the case of the green wall is obtained, but with similar values to those for riprap wall, from which we deduce that there is not a clear optimal solution, but an ensemble of compromise solutions that can be a solution to the problem in a more or less appropriate form. It is demonstrated this by applying requirement 1 , acceptable advantage of the VIKOR method. $Q(\mathrm{~A}(1))-Q(\mathrm{~A}(2))$, is lower than 0.333 , therefore the requirement 1 of acceptable advantage is not met. Therefore, as a solution to the decision-making problem, we suggest an ensemble of compromise solutions formed by the alternatives green retaining wall and riprap retaining wall. It should be remembered that the VIKOR method proposes an ensemble of compromise solutions to those alternatives, $\mathrm{A}(1), \mathrm{A}(2), \ldots, \mathrm{A}(\mathrm{M})$, that make $Q(\mathrm{~A}(\mathrm{M}))-Q(\mathrm{~A}(1))<$ $D Q$. For project 2, when the most important criterion is the cost, the best-valued solution is the green wall, being a close second (admissible solution) the riprap wall, therefore 
being both valid with VIKOR. However, in the case the importance of the construction performance is increased $(+3 \%)$, the optimal solution is the riprap retaining wall, and the garden retaining wall would be the second solution. With this analysis, we can see the sensibility of the method and its possible use when no characteristic is clearly predominant, like the landscape integration in the previous case. If the criteria weight is not defined, the strongest solution will be the riprap retaining wall, which is the best ranked or the second in all the cases. A strong solution is the one that is still admissible when the importance of the criteria changes.

When using TOPSIS, the green retaining wall is confirmed as the best-ranked solution and as the second option the riprap retaining wall, obtaining the following classification: Green retaining wall, $R_{j}=0.9991$; Riprap retaining wall, $R_{j}=0.5955$; Garden retaining wall, $R_{j}=0.5227$; Reinforced concrete retaining wall, $R_{j}=0.0005$. This way it is proven that the proposed method can be applied both in cases with different criteria importance and in cases in which the precedence is clear but the differences not so much.

\section{Results}

After applying the methodology (AHP + VIKOR methods) to two projects in different environments, in both cases, we obtained a compromise solution (or set of solutions) that remains stable in the case of changes in the weights of the selection criteria. In other words, the best-rank solution of type of retaining wall remains the best-ranked first or second whit different weighting criteria, which is why this solution is admissible when the importance of the criteria changes. In both projects, the ranking obtained by the VIKOR method is confirmed after the application of the TOPSIS method. Obtaining the green retaining as the first-rank solution and the rip rap retaining wall as the second-rank solution in the selection of retaining wall types for two different projects, one in a natural environment and other in design and construction of a new highway.

\section{Study Implications and Contributions}

The methodology developed first provides a systematic process for the identification of alternatives and selection criteria for the selection of types of retaining walls. It incorporates an exhaustive list of all the selection criteria that need to be considered and analyzed in the decision-making process, including the requirements of the construction process. This list of criteria, and their definition, may help other researchers and practitioners to include in the selection of best alternative in future projects for example for selection de typologies of bridges. Moreover, it is possible to systematically incorporate the importance of the different criteria according to the environment in which the structure is built since it is not the same as a structure being built in a natural environment as in a newly constructed highway with fewer environmental and space limitations.

\section{Discussion}

After applying the methodology to the case studies, it is appropriate to discuss whether some issues could improve the identification or weighting of criteria or the assessment of each alternative against each criterion. By that and concerning the selection of retaining wall typologies, the article provides a more objective process for the weighting of criteria than other previous investigations commented on in the review of the literature that is carried out by subjective assessments of the decision-maker and with qualitative scales. However, in any way, the weighting of criteria by paired comparisons (AHP method) has a subjective component, although this can be overridden with an appropriate number of decision-makers/experts or decision group. Therefore, for future research, it would be appropriate to modify the methodology for the selection of retaining walls by applying other methods of weighting selection criteria such as the entropy method, which does not involve the opinions of experts and increases objectivity, [45] and compare the results with the application of the AHP method with an appropriate number of decision-makers. On the other hand, the selection methodology has not taken into account the dependence of 
the criteria, so this issue should be analyzed to verify if the solutions obtained would vary and whether the methodology is appropriate $[26,35]$.

In the paper, all the typologies of retaining walls have been identified, as well as all the selection criteria, however, and to simplify the application of the methodology, the selection method has been applied to a reduced group of alternatives and criteria. For this reduced set of alternatives and criteria, a ranking of stable compromise solutions when there are changes in the weight of the criteria has been obtained, but it would be convenient to extend the application to a greater number of alternatives and criteria and to analyze the results. On this option, the rank reversal process should be analyzed when adding new alternatives or criteria to the previously chosen set. In this phenomenon, the ordering of alternatives inverts when an alternative is added or eliminated from the list of alternatives [46-49].

The TOPSIS method is applied to confirm the best-rank solution previously classified by the VIKOR method; however, the TOPSIS method has several disadvantages. One of them is that it requires the normalization of the values of the decision matrix to avoid the effect of the dimensionality of the assessments of the alternatives with respect to each criterion $[42,50]$. Another disadvantage of the TOPSIS method is that, when using the Euclidean distance to determine the distance of each alternative to positive ideal solutions and negative ideal solutions, it does not consider the correlation between criteria [51].

\section{Study Limitations and Future Research Directions}

As discussed in previous sections, one of the limitations of the study is the determination of criteria weights, which has been done according to the AHP method assuming criteria independence. In future research, this issue should be addressed so that it is studied how the correlation of the criteria influences the weighting of the criteria and to consider other methods of decision-making that allow this correlation to be taken account. Furthermore, in future studies, the methodology can be improved to avoid the phenomenon of "rank reversal" when an alternative is added or removed.

\section{Conclusions}

The methodology developed first provides a systematic process for the identification of alternatives and selection criteria for the selection of types of retaining walls. Thus, the application of the methodology allows identifying all the determining criteria in the selection of retaining walls, both minor and major importance criteria, and identifying the construction requirements that are often overlooked in the phase of design and selection of alternatives. The relative importance of the criteria for different projects is determined through paired comparisons. As result, a ranking of constructive solutions of retaining walls that is still admissible when the importance of the criteria changes is obtained.

Case study validates the combined sequential use of two decision-making methods for selecting the best constructive solution for a wall in different and specific situations by proving that a solid and transparent ensemble of criteria can be taken into account, such as the environment, with the construction performance and the costs through an objective and transparent process, making clear which are the expressed preferences and their importance in the process. Moreover, verification of the validity of the methodology shows the stability of the solutions obtained, even if there are changes in the weighting of the criteria.

The suggested decision-making process is based on data that are easy to obtain and to allow the evaluation of alternatives according to qualitative criteria. As a result of this, the fact of obtaining a solution as a result of the application of a systematic process that is relatively objective will allow-in situations of disagreements among different groups of interests, stakeholders-to justify the adopted solution. As a result of the research, a methodology for the selection of types of retaining walls is provided, which can be useful for public administrators, designers, project managers, and constructors. 
It should be noted that the methodology can be applied to the selection of other infrastructures in which the design and construction requirements may determine that particular alternatives are not suitable or are suitable to a lesser extent, for example, for the selection of bridge types.

Author Contributions: Conceptualization, B.M.-M., J.O., and M.G.R.; methodology, B.M.-M.; software, B.M.-M.; validation, B.M.-M., J.O., and M.G.R.; formal analysis, A.L.-G.; investigation, B.M.-M.; writing—original draft preparation, B.M.-M.; writing—review and editing, B.M.-M. and A.L.-G. All authors have read and agreed to the published version of the manuscript.

Funding: This research received no external funding.

Institutional Review Board Statement: Not applicable.

Informed Consent Statement: Not applicable.

Data Availability Statement: Data is contained within the article or supplementary material.

Conflicts of Interest: The authors declare no conflict of interest.

\section{References}

1. Spanish Ministry of Development. Tipologia de Muros de Carretera, 1st ed.; MINISTERIO DE FOMENTO: Madrid, Spain, 1999.

2. Anderson, S. Chapter 62 Types of retaining walls. In ICE Manual; ICE Publishing: London, UK, 2012; pp. 959-968.

3. South Carolina Department of Transportation (SCDOT). SCDOT Geotechnical Design Manual; South Carolina Department of Transportation (SCDOT): North Charleston, SC, USA, 2010.

4. Choi, M.; Lee, G. Decision tree for selecting retaining wall systems based on logistic regression analysis. Autom. Constr. 2010, 19, 917-928. [CrossRef]

5. $\quad$ Pons, J.J.; Penadés-Plà, V.; Yepes, V.; Martí, J.V. Life cycle assessment of earth-retaining walls: An environmental comparison. J. Clean. Prod. 2018, 192, 411-420. [CrossRef]

6. Liou, J.J.H.; Lu, M.T.; Hu, S.K.; Cheng, C.H.; Chuang, Y.C. A hybrid MCDM model for improving the electronic health record to better serve client needs. Sustainability 2017, 9, 1819. [CrossRef]

7. Chen, Y.; Kilgour, D.M.; Hipel, K.W. Screening in multiple criteria decision analysis. Decis. Support Syst. 2008, 45, 278-290. [CrossRef]

8. Anderson, S.A.; Alzamora, D.; Demarco, M.J. Asset management systems for retaining walls. In Geo-Velopment: The Role of Geological and Geotechnical Engineering in New and Redevelopment Projects_Proceedings of the 2008 Biennial Geotechnical Seminar; ASCE Library: Denver, CO, USA, 2008; pp. 162-177. [CrossRef]

9. Zastrow, P.; Molina-Moreno, F.; García-Segura, T.; Martí, J.V.; Yepes, V. Life cycle assessment of cost-optimized buttress earthretaining walls: A parametric study. J. Clean. Prod. 2017, 140, 1037-1048. [CrossRef]

10. Khan, A.J.; Sikder, M. Design Basis and Economic Aspects of Different Types of Retaining Walls. J. Civil Eng. (IEB) 2004, 32, 17-34.

11. Shehata, H.F. Retaining walls with relief shelves. Innov. Infrastruct. Solut. 2016, 1, 1-13. [CrossRef]

12. Ríos, S. Algunos procesos y problemas en la Ciencia de la decisión. Rev. Matemática Complut. 1988, 11. Available online: http:/ / www.mat.ucm.es/serv/revmat/vol11-1/vol11-1g.html (accessed on 11 July 2020).

13. Penadés-Plà, V.; García-Segura, T.; Martí, J.; Yepes, V. A Review of Multi-Criteria Decision-Making Methods Applied to the Sustainable Bridge Design. Sustainability 2016, 8, 1295. [CrossRef]

14. Cheney, J.N. Utilizing the Decision Matrix to Introduce the Engineering Design Process; Center for Teaching Excellence, United States Military Academy, West Point; United States Military Academy: Orange County, NY, USA, 2009.

15. Triantaphyllou, E. Multi-Criteria Decision Making Methods: A Comparative Study; Springer: Boston, MA, USA, 2000 ; Volume 44.

16. Siskos, E.; Tsotsolas, N. Elicitation of criteria importance weights through the Simos method: A robustness concern. Eur. J. Oper. Res. 2015, 246, 543-553. [CrossRef]

17. Sierra, L.A.; Yepes, V.; Pellicer, E. A review of multi-criteria assessment of the social sustainability of infrastructures. J. Clean. Prod. 2018. [CrossRef]

18. Saaty, T.L. How to make a decision: The analytic hierarchy process. Eur. J. Oper. Res. 1990, 48, 9-26. [CrossRef]

19. Fülöp, J. Introduction to Decision Making Methods; BDEI-3 Workshop: Washington, DC, USA, 2005; pp. 1-15.

20. Podvezko, V. The comparative analysis of MCDA methods SAW and COPRAS. Eng. Econ. 2011, 22, 134-146. [CrossRef]

21. Opricovic, S.; Tzeng, G.H. Compromise solution by MCDM methods: A comparative analysis of VIKOR and TOPSIS. Eur. J. Oper. Res. 2004, 156, 445-455. [CrossRef]

22. Opricovic, S.; Tzeng, G.H. Extended VIKOR method in comparison with outranking methods. Eur. J. Oper. Res. 2007, 178, 514-529. [CrossRef]

23. Shumaiza; Akram, M.; Al-Kenani, A.N.; Alcantud, J.C.R. Group decision-making based on the VIKOR method with trapezoidal bipolar fuzzy information. Symmetry 2019, 11, 1313. [CrossRef] 
24. Badi, I.; Ballem, M.; Shetwan, A. Site selection of desalination plant in Libya by using Combinative Distance-Based Assessment (CODAS) method. Int. J. Qual. Res. 2018, 12, 609-624.

25. Karaşan, A.; Boltürk, E.; Kahraman, C. A novel neutrosophic CODAS method: Selection among wind energy plant locations. J. Intell. Fuzzy Syst. 2019, 36, 1491-1504. [CrossRef]

26. Saaty, T.L. Decision Making with Dependence and Feedback: The Analytic Network Process; RWS Publications: Pittsburgh, PA, USA, 1996; p. 370, ISBN 0-9620317-9-8.

27. Saaty, T.L. Fundamentals of the analytic network process-Multiple networks with benefits, costs, opportunities and risks. J. Syst. Sci. Syst. Eng. 2004, 13, 348-379. [CrossRef]

28. Costa, C.A.B.E.; Vieira, A.C.L.; Nóbrega, M.; Quintino, A.; Oliveira, M.D.; Costa, J.B.E. Collaborative Value Modelling in corporate contexts with MACBETH. Procedia Comput. Sci. 2019, 162, 786-794. [CrossRef]

29. Giron, X.; Madrid, D. Comparación de Dos Métodos de Toma de Decisiones Multicriterio: Macbeth y Promethée; Universitat Rovira i Virgili: Tarragona, Spain, 2008.

30. Roy, B. Classement et choix en présence de points de vue multiples. RAIRO Oper. Res. Rech. Opérationnelle 1968, 2, 57-75. Available online: http:/ / www.numdam.org/conditions (accessed on 16 July 2020). [CrossRef]

31. Roy, B. The outranking approach and the foundations of electre methods. Theory Decis. 1991, 31, 49-73. [CrossRef]

32. Brans, J.-P.; Smet, Y. PROMETHEE Methods; Chapter 1; Multiple Criteria Decision Analysis. International Series in Operations Research \& Management Science; Springer: New York, NY, USA, 2016; Volume 233, ISBN 978-1-4939-3094-4. [CrossRef]

33. Baker, D.; Bridges, D.; Hunter, R.; Johnson, G.; Krupa, J.; Murphy, J.; Sorenson, K. Guidebook to Decision-Making Methods; U.S. Department of Energy: Washington, DC, USA, 2001.

34. Yepes, V.; García-Segura, T.; Moreno-Jiménez, J.M. A cognitive approach for the multi-objective optimization of RC structural problems. Arch. Civ. Mech. Eng. 2015, 15, 1024-1036. [CrossRef]

35. Saaty, R.W. Decision Making in Complex Environments. The Analytic Network Process (ANP) for Decision Making with Dependence and Feedback; RWS: Pittsburgh, PA, USA, 2016; ISBN 1-888603-00-3.

36. Belošević, I.; Kosijer, M.; Ivić, M.; Pavlović, N. Group decision making process for early stage evaluations of infrastructure projects using extended VIKOR method under fuzzy environment. Eur. Transp. Res. Rev. 2018, 10. [CrossRef]

37. Sennaroglu, B.; Varlik Celebi, G. A military airport location selection by AHP integrated PROMETHEE and VIKOR methods. Transp. Res. Part D Transp. Environ. 2018, 59, 160-173. [CrossRef]

38. Ramezanianpour, A.A.; Tabatabaei, S.A.; Pourlak, M.; Abareshi, M. AHP-VIKOR Bridge Structural System Selection in Urban Areas Tehran Interchanges Case Study. Ambient Sci. 2016, 3. [CrossRef]

39. Awasthi, A.; Omrani, H.; Gerber, P. Investigating ideal-solution based multicriteria decision making techniques for sustainability evaluation of urban mobility projects. Transp. Res. Part A Policy Pract. 2018, 116, 247-259. [CrossRef]

40. Mardani, A.; Jusoh, A.; Zavadskas, E.; Cavallaro, F.; Khalifah, Z. Sustainable and Renewable Energy: An Overview of the Application of Multiple Criteria Decision Making Techniques and Approaches. Sustainability 2015, 7, 13947-13984. [CrossRef]

41. Jelokhani-Niaraki, M.; Malczewski, J. Decision complexity and consensus in Web-based spatial decision making: A case study of site selection problem using GIS and multicriteria analysis. Cities 2015, 45, 60-70. [CrossRef]

42. Ceballos, B.; Lamata, M.T.; Pelta, D.; Sanchez, J.M. El método TOPSIS Relativo vs. Absoluto. In Rect@ Rev. Electrónica Comun. y Trab. ASEPUMA, ISSN-e 1575-605X; 2013; Volume 14, pp. 181-192. Available online: https://dialnet.unirioja.es/servlet/articulo? codigo $=4743030$ \&info=resumen\&idioma $=$ ENG (accessed on 15 December 2020).

43. San Cristóbal, J.R. Contractor Selection Using Multicriteria Decision-Making Methods. J. Constr. Eng. Manag. 2012, 138, 751-758. [CrossRef]

44. Spanish Ministry of Development. Guía Para el Proyecto y la Ejecución de Muros de Escollera en Obras de Carretera; Spanish Ministry of Development: Madrid, Spain, 2006.

45. Lee, H.C.; Chang, C. Comparative analysis of MCDM methods for ranking renewable energy sources in Taiwan. Renew. Sustain. Energy Rev. 2018, 92, 883-896. [CrossRef]

46. García-Cascales, M.S.; Lamata, M.T. On rank reversal and TOPSIS method. Math. Comput. Model. 2012, 56, 123-132. [CrossRef]

47. Mousavi-Nasab, S.H.; Sotoudeh-Anvari, A. A new multi-criteria decision making approach for sustainable material selection problem: A critical study on rank reversal problem. J. Clean. Prod. 2018, 182, 466-484. [CrossRef]

48. Ceballos, B.; Pelta, D.A.; Lamata, M.T. Rank Reversal and the VIKOR Method: An Empirical Evaluation. Int. J. Inf. Technol. Decis. Mak. 2018, 17, 513-525. [CrossRef]

49. Wang, Y.M.; Luo, Y. On rank reversal in decision analysis. Math. Comput. Model. 2009, 49, 1221-1229. [CrossRef]

50. Çelen, A. Comparative analysis of normalization procedures in TOPSIS method: With an application to Turkish deposit banking market. Informatica 2014, 25, 185-208. [CrossRef]

51. Villanueva Ponce, R.; García Alcaraz, J.L. Evaluación de Tecnología utilizando TOPSIS en Presencia de Multi-colinealidad en Atributos: ¿Por qué usar distancia de Mahalanobis? Rev. Fac. Ing. Univ. Antioquia 2013, 67, 31-42. 